\title{
An Empirical Study Regarding the Satisfaction Level of Taiwanese Youth Tourists to Japan
}

\author{
Fumihiko Isada ${ }^{1, *}$, Han-Ching Lin ${ }^{2}$, Yuriko Isada ${ }^{3}$ \\ ${ }^{1}$ The Faculty of Informatics, Kansai University, Japan \\ ${ }^{2}$ Department of Marketing and Logistics Management, Chihlee University of Technology, Taiwan \\ ${ }^{3}$ School of Policy Studies, Kwansei Gakuin University, Japan
}

Copyright $(2017$ by authors, all rights reserved. Authors agree that this article remains permanently open access under the terms of the Creative Commons Attribution License 4.0 International License

\begin{abstract}
The objective of this research is to analyze quantitatively the evaluation and background factors for tourist sites in Japan by the younger age group of Taiwanese visitors to Japan, and to consider a future subject. The questionnaire was designed based on consumer-behavior theory, service marketing, etc. as a theory relevant to sightseeing. It turned out that the factors that constitute especially quality of service and experience value are closely related to a revisit intention etc. In addition, as compared with other countries, the factors by which tourist sites in Japan were evaluated highly, and not highly, became clear among those factors.
\end{abstract}

Keywords International Tourism, AISAS ${ }^{(\mathrm{R})}$, SERVQUAL, Experience Economy

\section{Introduction}

The objective of this research is to analyze quantitatively the evaluation and background factors for tourist sites in Japan by the younger age group of Taiwanese visitors to Japan, and to consider a future subject. The research task is to clarify the factors that raise the satisfaction level of international tourists who visit Japan based on the precedence research studies. The questionnaire was designed based on consumer-behavior theory, service marketing, etc. as a theory relevant to sightseeing.

For years, there have been very few international tourists visiting tourist sites in Japan as compared with other countries. According to the statistical data of the Japan National Tourism Organization [1], the average annual number of international tourists who visited Japan in the 20 years following 1990 was about 5 million people. In comparison, tens of millions of international tourists visit countries in Western Europe, such as France and Italy, in one year. However, the number of international visitors to Japan increased rapidly in the last three years. The number of international visitors exceeded 10 million for the first time in 2013, and reached about 20 million in 2015. As a background to this rapid transition, two short-term factors are broadly considered. The first is the rapid fall in the Japanese yen against foreign currency. This is based on the large relaxation of the tight money control policy of the country. Another factor is the steep rise in tourists from the Chinese mainland. The Chinese wealthy and the middle classes, who have increased in number in connection with the rapid Chinese economic growth, began to travel not only to Japan but all around the world. However, there is no telling when such a factor will change in the long run. On the other side, many tourists have continued to visit Japan from Taiwan for many decades. Although the total population of Taiwan is only several percent of that of mainland China, there were more visitors to Japan continuously till 2014 than the number of visitors from mainland China. A Taiwanese tourist has been a very precious resource over many years for every tourist site in Japan.

Currently, the scale and the growth potential of the tourism industry are greatly anticipated from the viewpoint of the economic growth of Japan. The conventional manufacturing-trade model as an economic growth model for Japan have faced difficulties with increased labor costs and other cost increases. Therefore, structural transformation and the advancement to a service industry were rapidly progressed. Moreover, since the low birthrate and longevity of the population are also aggravated currently, the inbound style of the economic-growth model which takes in overseas economic growth in the country is expected. However, in the current situation, neither various tourist sites nor government offices can respond sufficiently to the present upsurge in tourists. In the first place, the hard infrastructure is insufficient, such as accommodation and transportation, and every tourist site is engaged in taking countermeasures. Furthermore, the soft infrastructure is also falling behind, the suitable marketing and the ideal hospitality to each international visitor are still underdeveloped, and various problems have occurred at tourist sites. 
In the tourism industry in Japan, the trait of hospitality peculiar to the Japanese people is often described as "OMOTENASHI." For example, in the bidding for the Tokyo Olympic Games in 2020, the word "OMOTENASI" was used as a keyword to attract attention. However, what "OMOTENASI" expresses is ambiguous and disjointed. In addition, the Japanese style hospitality that Japanese people have named "OMOTENASI" is a characteristic reception style mainly formed towards Japanese tourists in Japan. "OMOTENASI" may not be effective for the international visitor to Japan. In fact, the reception manner that Japanese people think is good may sometimes seem inappropriate to international visitors' habitual practice. At least, if the Japanese-style reception is an effective way to attracting international tourists, it cannot explain the fact that there were very few international visitors to Japan until a few years ago. Probably, it is more important to grasp international tourists' needs in various opportunities fairly and to accumulate suitable marketing than to depend on such an ambiguous notion.

In this research, Taiwanese visitors were surveyed on the reason or subject of their visit to Japan. Since many Taiwanese tourists have visited Japan over many years now, the Taiwanese are thought to know well the merits or demerits of sightseeing in Japan. Taiwanese university students who were studying Japanese were especially observed. They are considered to know Japan well and comparatively to have considerable trip experience to Japan. Therefore, the questionnaire regarding tourist sites recently visited was administered to them.

\section{Precedence Research}

In this research, the research concepts, theories, and models, such as the consumer-buying process, quality of service, and experience economy, were mainly used as an analytical framework regarding the background factors to the tourists' satisfaction level.

\subsection{Consumer-buying Process}

A series of research studies indicate a model about the process leading to the consumer's purchase, such as classical theories about consumers' buying behavior of goods and service. The results of the research have accumulated for 100 years or more. Although there are various academic critiques, there is merit in the model being easy to explain the point that stimulates the consumer's purchase. Therefore, a consumer-buying process model is used widely, and various kinds of models have been proposed [2].

Dentsu Inc. [3] advocated the application of the $\operatorname{AISAS}^{(\mathrm{R})}$ model, after the appearance of the Internet. The AISAS ${ }^{(R)}$ model categorizes consumer behavior into five elements: attention, interest, search, action, and share. The birth of on-line catalogue-selling sites and price comparison websites resulted in the need to consider the process of searching before that of buying. Consumers share information through blogs, social networking sites, sharing sites, etc. after purchasing, and this helps other consumers decide on purchases.

\subsection{Quality of Service}

As a comprehensive quality measure model on service, the SERVQUAL model is currently used widely. Parasuraman, Zeithaml, and Berry [4] performed an analytical and quantitative surveillance study using a questionnaire. As a result of repeating an exploratory factor analysis using the obtained data, they were finally combined into five dimensions. The content of the items making up each of SERVQUAL's five dimensions suggest the following labels and concise definitions for the dimensions.

"Tangibles" is a dimension regarding physical facilities, equipment, and appearance of personnel. The following keywords are given as an example of a question item: up-to-date equipment, visually appealing, well dressed, appear neat, and in keeping with the type of services provided. "Reliability" is a dimension regarding the ability to perform the promised service dependably and accurately. The following keywords are given as an example of a question item: promise, certain time, sympathetic and reassuring for customers in trouble, dependable, and keeping accurate records. "Responsiveness" is a dimension regarding willingness to help customers and provide prompt service. The following keywords are given as an example of a question item: clear explanation of the services, expect prompt service, willing to help customers, and respond to customer requests promptly. "Assurance" is a dimension regarding the knowledge and courtesy of employees and their ability to inspire trust and confidence. The following keywords are given as an example of a question item: trust, feel safe, polite, and adequate support. "Empathy" is a dimension regarding caring and individualized attention the firm provides its customers. The following keywords are given as an example of a question item: individual attention, personal attention, knowing the needs of the customers, the customers' best interests at heart, and convenient operating hours.

\subsection{Experience Economy}

According to Pine and Gilmore [5], a customer's view of value has evolved from commodity to product, from product to service, and from service to experience. The stage of experience has aspects that are very different from those of the other stages, and greater economic value emerges from the experience economy. The customer experience is categorized into four realms of experience. The 4Es model of experience consists of "Entertainment," "Education," "Esthetics," and "Escapism," which will create a meaningful experience.

"Entertainment" is the passive aspect of experience, where the customers enjoy the experience of watching others. 
Customers are associated with a performer or an event, which allows them to simply enjoy it by themselves. The second field of experience is "Education," which means increasing customer skills through active participation in the experience. The purpose of this experience is to learn something new. "Esthetics" is the passive aspect of experience. The purpose is just to be there, being able to use the senses and take in the experience. The "Escapist" experience is an active aspect, which involves a higher level of customer engagement and active participation in real environments.

Lemon \& Verhoef [6] insisted the importance of understanding customer experience and the customer journey over time for firms. They examine existing definitions and conceptualizations of customer experience as a construct and provide a historical perspective of the roots of customer experience within marketing, such as customer buying behavior process models, customer satisfaction and loyalty, and service quality. Dziewanowska [7] presents the extended literature review on consumer experiences in online and offline shopping environment leading to identification of key dimensions of consumer experiences and providing an overview of current state of research in the identified areas. Theoretical and empirical research on models and measurement tools of consumer experiences in the shopping context is presented and discussed, which include consumer behavior and service quality.

\section{Survey Hypothesis}

Next, the hypothesis was examined based on the above-mentioned precedence research studies about the factors that raise the satisfaction level of international tourists who visit Japan in order to design the questionnaire.

Here, since the objective of the research was to increase the number of international visitors to Japan, the satisfaction level was defined as a tourist who visits Japan again and again, or wants to come again. In addition to a person's intention to revisit, the recommendation to other people was also included in the measurement item of the satisfaction level. Generally, sightseeing is made up of experience goods with asymmetric information according to economics. As with a novel or a movie, the value is unclear before the consumers have actually purchased and experienced the good. In the purchase of such experience goods, other consumers' word-of-mouth evaluation and recommendation are thought to be connected with the decision to buy.

Next, the relationship between the revisit intention to a tourist site or the inclination to make a recommendation, and the consumer buying process are considered. If consumers' "attention" is effectively stimulated through various media, such as television broadcasting, the Internet, and travel magazines, the consumers' "interest" may increase and the desire to visit and revisit may increase. In addition, if the information corresponding to an individual liking is acquired by the information service for which consumers tend to "search," the needs of consumers, such as visit desire, experience desire, eating-and-drinking desire, and revisit desire, may be raised. Furthermore, if consumers can exchange, "share," and communicate their experience of a travel destination using social networking services, consumer experience forums, etc. on the Internet, while the pleasure of the person himself/herself increases, other people's "attention" and "interest" may also be stimulated. The following hypothesis can be considered from the above assumption.

\section{H1. Each component of a consumer-buying process} raises the satisfaction level of the tourist to Japan.

Next, the relationship between the quality of service and the sightseeing satisfaction level is considered. The management factor in service marketing is considered as important, and is classified with a person, an offer process, and a physical factor in many cases rather than $4 \mathrm{P}$ (Product, Promotion, Place, Price) in physical goods [8]. This is because there are peculiar traits, such as "intangibility," "inseparability," "heterogeneity," and "perishability," in service goods unlike physical goods [9]. In many cases, the quality that consumers perceive from sightseeing is closely related to the procedure of the working staff, who provide the services at a tourist site, in the accommodation, or catering service, etc. Consumers' satisfaction level is affected by the reception of the persons who provide the service, and an offer process, in short, is a "moment of truth" [10].

According to the service offer model of SERVQUAL, the first dimension is "Tangibles." Regarding places of natural beauty and historic interest, leisure facilities and hotel restaurants in a tourist site, the facilities that are available at the time of a service offer, and the staff on duty, when external appearance and form are in order, a tourist's satisfaction level can be raised.

The next dimension is "Reliability." This can raise consumers' satisfaction level when the service that consumers visiting the tourist site expect is promptly performed, and the quality is consistent. In international sightseeing, since the habitual practice of a destination is unfamiliar, a tourist's anxiety tends to increase about whether the service provided is really acceptable, and in cases where difficulties arise, it is much more likely to increase anxiety. The height of "reliability" is a service that is provided exactly, without being kept waiting, or an equivalent alternative is prepared in the case of a difficulty, may increase satisfaction.

The next dimension is "Responsiveness." At a tourist site, consumers' satisfaction level can be raised by a purveyor of services who provides support and prompt service for a customer positively. Especially in international sightseeing, where a traveler is unfamiliar with the area, or if a traveler does not understand the local language, it is difficult to get information. Consumers' satisfaction may be raised by clear and precise information being offered on a service offer in a traveler's native language etc., or staffs deal with a 
customer's request positively.

Next, is "Assurance". The purveyor of services who provides knowledge and courtesy, giving a customer a sense of reliability and sense of security can raise consumers' satisfaction level. Especially in international tourism, it is possible to increase visitors' anxiety, if they are met with unhelpful staff in the store or hotel. Consumers' satisfaction may be increased if working staff are courteous, have abundant knowledge and deal with difficulties appropriately.

Finally, is "Empathy". When staff take care from the bottom of their heart through a communication to every customer, the consumers' satisfaction level can be raised. Especially in international tourism, pleasant communication with local staff which form the first contact, and a sense of hospitality from the bottom of their heart may be the nicest points of a trip, and may raise consumers' satisfaction. The following hypothesis can be considered from the above assumption.

H2. Each component of the quality of service raises the satisfaction level of the tourist to Japan.

Next, the relationship between the experience economy and sightseeing satisfaction level is considered. First of all, sightseeing is composed of experience goods. It is thought that the experience economy theory that discusses the source of consumer value by an experience or memories instead of consumer value by the consumption and possession of a physical good has a high relevance to sightseeing.

According to the experience economy model, four factors, such as "Entertainment," "Education," "Esthetics," and "Escapism," raise the experience value for consumers. Various kinds of show, play, other events, etc. in a tourist site may be the major components of a trip, and those "Entertainments" may raise consumers' satisfaction.

In addition, when a tourist not only merely has fun, but acquires new knowledge etc. through sightseeing, the value of sightseeing may increase. For example, the skiing classroom, the ceramic art experience, etc. are typical. It is an intellectual pleasure to get to know the tradition in a historic scene, a raw material, a recipe, a tableware, a decoration unique to the locality in a restaurant, etc., and it may further increase the goodness of a historic scene or a dish, and may raise consumers' satisfaction.

Furthermore, at a tourist site, the major component of a trip is to enjoy the beautiful scenery, buildings, showpieces, etc. Visiting beautiful rows of houses, rich nature, a museum exhibit, etc., or enjoying the cosmetics service unique to a locality, etc. may also raise consumers' satisfaction.

It is also one of the pleasures of a trip to forget everyday life during sightseeing and to experience something out of the ordinary. The amazing experience of a unique mountain or river, spelunking, etc., the scary ride in an amusement park, a gamble, extreme sports, etc. may be examples of "escapist" experiences, and may raise consumers' satisfaction. The following hypothesis can be considered from the above assumption.
H3. Each component of the experience economy raises the satisfaction level of the tourist to Japan.

Next, the goodness and the subject of Japan for Taiwanese tourism are assumed. The reason for many Taiwanese to visit tourist sites in Japan may be that the Taiwanese feel the unique value of tourist sites in Japan is one possibility. And an evaluation of some components of the above-mentioned consumer-buying process, quality of service, or an experience value may be higher than an evaluation of the tourist sites of other countries.

Of course, there is a possibility that the Taiwanese have selected Japan only for the reason of convenience. For a selection of a tourist site, convenience, such as the costs and a short travel time, and easy transportation, may be of primary importance. The following hypotheses can be considered from the above assumption.

H4. For the Taiwanese tourist, tourist sites in Japan are excellent in some part of the consumer-buying process, quality of service, or the experience values as compared with the tourist sites of other countries.

H5. For a Taiwanese tourist, the attraction of tourist sites in Japan is convenience (cheap, short, and nearby).

\section{Search Result}

\subsection{The Synopsis of a Search Result}

The questionnaire was implemented in Taiwan in order to verify each above-mentioned hypothesis. The first question item of the questionnaire asked about the overseas or domestic city visited recently to do the sights. The satisfaction level of the sightseeing as an objective variable was set up. In addition, based on the above-mentioned hypotheses, each component of a consumer-buying process, quality of service, experience economy, and convenience were set up as an explanatory variable. A few question items were respectively set up about each of the above-mentioned hypotheses. All of the objective variables and explanatory variables were measured using a five-point Likert scale. The questionnaire was administered to Taiwanese university students living in Taipei and the suburbs. The survey period was December, 2015. Excluding respondents with many deficit values, etc., the number of effective responses to the survey was 172 persons. SPSS by International Business Machines (Ver. 23) was used for each statistical procedure in the following analyses.

\subsection{A distribution of Destinations}

Table 1. Destination

\begin{tabular}{|c|c|}
\hline Place & number \\
\hline Japan & 56 \\
\hline China, South Korea & 21 \\
\hline Other Asia & 8 \\
\hline West & 3 \\
\hline Total & 88 \\
\hline
\end{tabular}


The distribution status of the overseas destinations of the students is shown in table 1 . The main overseas destinations for Taiwanese students in the survey were Japan, China, South Korea, and other Southeast Asian countries, with Japan being the most popular.

\subsection{The result of Principal Component Analysis}

First, regarding the questionnaire responses, after evaluating the ceiling effect, the floor effect, and a reliability scale, each question item group regarding the objective variable and an explanatory variable was collected by principal component analysis, respectively. As a reliability scale, the Cronbach's alpha was 0.887. One principal component each for which the Eigen value is one or more respectively, was extracted for the objective variable and each explanatory variable group as a result of the principal component analysis.

\subsection{Test of Significance}

Next, it was verified whether each principal component score would have a significant difference between travel destinations. First, the significant difference was examined between the domestic tour and the overseas trip. The result is as in table 2. First, the satisfaction level of the overseas trip was significantly high. Next, the overseas trip was significantly higher for "Attention,", "Interest,", and "Share" among the consumer-buying processes.

Table 2. Difference between domestic and overseas

\begin{tabular}{|c|c|c|c|c|}
\hline $\begin{array}{c}\text { Principal } \\
\text { Component }\end{array}$ & $\begin{array}{l}\text { Domestic } \\
\text { (mean) }\end{array}$ & $\begin{array}{c}\text { Overseas } \\
\text { (mean) }\end{array}$ & $t$-value & $\begin{array}{c}\text { Significance } \\
\text { Level } \\
(* *: 1 \% \\
*: 5 \%)\end{array}$ \\
\hline $\begin{array}{c}\text { Satisfaction } \\
\text { level }\end{array}$ & -0.1 & 0.3 & -3.370 & $* *$ \\
\hline Attention & 0.1 & 0.5 & -2.927 & $* *$ \\
\hline Interest & 0.2 & 0.6 & -3.127 & $* *$ \\
\hline Search & -0.0 & 0.2 & -1.912 & \\
\hline Share & 0.0 & 0.4 & -2.986 & $* *$ \\
\hline Tangibles & -0.5 & -0.7 & 2.244 & $*$ \\
\hline Reliability & 0.2 & 0.4 & -1.226 & \\
\hline Responsiveness & -0.8 & -0.7 & -.935 & \\
\hline Assurance & 0.3 & 0.3 & -.650 & \\
\hline Empathy & 0.2 & 0.4 & -1.335 & \\
\hline Entertainment & -0.0 & 0.2 & -1.519 & \\
\hline Education & 0.2 & 0.3 & -.750 & \\
\hline Esthetics & 0.2 & 0.2 & .307 & \\
\hline Escapism & 0.1 & 0.3 & -1.501 & \\
\hline Convenience & 0.5 & 0.6 & -.309 & \\
\hline
\end{tabular}

In addition, although the overseas trip was significantly lower for "tangibles" among qualities of service, there was no other significant difference. There was no significant difference also for experience value. It seems that the interest level of an overseas trip is high generally for a Taiwanese student - advertising etc. is quite prominent, the satisfaction level after an overseas trip is also high, and the information exchange by social networking etc. On the other side, it seemed that the Taiwanese student sensed that an overseas trip and a domestic tour are not so much different regarding quality of service and experience value from the destination.

Table 3. Difference between Japan and other destinations

\begin{tabular}{|c|c|c|c|c|}
\hline $\begin{array}{c}\text { Principal } \\
\text { Component }\end{array}$ & $\begin{array}{c}\text { Japan } \\
\text { (mean) }\end{array}$ & $\begin{array}{c}\text { Other } \\
\text { destinations } \\
\text { (mean) }\end{array}$ & $t$-value & $\begin{array}{c}\text { Significant } \\
\text { Level } \\
(* *: 1 \%, \\
*: 5 \%)\end{array}$ \\
\hline $\begin{array}{c}\text { Satisfaction } \\
\text { level }\end{array}$ & 0.6 & -0.1 & 2.849 & $* *$ \\
\hline Attention & 0.6 & 0.3 & 1.585 & \\
\hline Interest & 0.5 & 0.7 & -.757 & \\
\hline Search & 0.3 & 0.1 & 1.077 & \\
\hline Share & 0.4 & 0.4 & -.298 & \\
\hline Tangibles & -0.8 & -0.6 & -1.040 & \\
\hline Reliability & 0.5 & 0.2 & 1.289 & \\
\hline Responsiveness & -0.7 & -0.6 & -.630 & \\
\hline Assurance & 0.5 & 0.0 & 2.255 & $*$ \\
\hline Empathy & 0.5 & 0.2 & 1.539 & \\
\hline Entertainment & 0.0 & 0.4 & -1.686 & \\
\hline Education & 0.4 & 0.1 & 1.398 & \\
\hline Esthetics & 0.3 & -0.0 & 2.080 & $*$ \\
\hline Escapism & 0.4 & 0.3 & .259 & \\
\hline Convenience & 0.7 & 0.4 & 2.147 & $*$ \\
\hline
\end{tabular}

Next, the test of significance between the overseas trip to Japan and the overseas trip apart from Japan was performed for Taiwanese students. The result is as in the table 3. First, the satisfaction level for Japan was significantly high. In addition, it was significantly high for "assurance" of quality of service, and "esthetics" of an experience value, and convenience. However, there was no significant difference in all the other items. It seemed that the Taiwanese student thought that for the sightseeing in Japan, the facilities, streets, etc. are clean, and the staff are courteous, and it is a near and convenient travel destination as compared with other countries. On the other side, for qualities of service or experience values other than the above, Japan was not evaluated well. 


\subsection{Correlation analysis}

Table 4. Result of correlation analysis $(\mathrm{N}=56)$

\begin{tabular}{|c|c|c|c|c|c|c|c|c|c|c|c|c|c|c|c|}
\hline Variables & 1 & 2 & 3 & 4 & 5 & 6 & 7 & 8 & 9 & 10 & 11 & 12 & 13 & 14 & 15 \\
\hline Satisfaction Level & 1 & & & & & & & & & & & & & & \\
\hline Attention & $.397^{* *}$ & 1 & & & & & & & & & & & & & \\
\hline Interest & .227 & .262 & 1 & & & & & & & & & & & & \\
\hline Search & $.341^{*}$ & $.471^{* *}$ & $.466^{* *}$ & 1 & & & & & & & & & & & \\
\hline Share & $.277^{*}$ & $.626^{* *}$ & .207 & $.371^{* *}$ & 1 & & & & & & & & & & \\
\hline Tangibles & -.248 & -.251 & $-.313^{*}$ & -.184 & -.174 & 1 & & & & & & & & & \\
\hline Reliability & $.425^{* *}$ & $.451^{* *}$ & .124 & $.353^{* *}$ & .253 & -.096 & 1 & & & & & & & & \\
\hline Responsiveness & -.166 & -.116 & -.146 & -.054 & -.102 & .261 & -.075 & 1 & & & & & & & \\
\hline Assurance & $.483^{* *}$ & $.427^{* *}$ & .128 & $.318^{*}$ & .124 & -.200 & $.610^{* *}$ & -.036 & 1 & & & & & & \\
\hline Empathy & $.508^{* *}$ & $.455^{* *}$ & .110 & $.347^{* *}$ & .107 & $-.407^{* *}$ & $.581^{* *}$ & -.045 & $.691^{* *}$ & 1 & & & & & \\
\hline Entertainment & .183 & $.446^{* *}$ & $.413^{* *}$ & $.351^{* *}$ & $.473^{* *}$ & $-.357^{* *}$ & .239 & -.100 & .188 & .230 & 1 & & & & \\
\hline Education & $.412^{* * *}$ & $.415^{* *}$ & $.347^{* *}$ & $.344^{* *}$ & $.315^{*}$ & -.019 & $.356^{* *}$ & -.166 & $.482^{* *}$ & $.420^{* *}$ & .244 & 1 & & & \\
\hline Esthetics & $.569^{* * *}$ & $.513^{* *}$ & .232 & $.399^{* *}$ & .233 & $-.304^{*}$ & .205 & -.101 & $.494^{* *}$ & $.529^{* *}$ & $.330^{*}$ & $.485^{* *}$ & 1 & & \\
\hline Escapism & $.365^{* *}$ & $.545^{* *}$ & $.384^{* *}$ & $.408^{* *}$ & $.487^{* *}$ & $-.359^{* *}$ & $.324^{*}$ & -.124 & $.418^{* *}$ & $.378^{* *}$ & $.582^{* *}$ & $.446^{* *}$ & $.389^{* *}$ & 1 & \\
\hline Convenience & $.399^{* *}$ & $.310^{*}$ & $.286^{*}$ & .191 & .201 & -.068 & $.274^{*}$ & .130 & .212 & $.308^{*}$ & $.350^{* *}$ & $.306^{*}$ & $.379^{* *}$ & $.288^{*}$ & 1 \\
\hline$M$ & 0.566 & 0.580 & 0.543 & 0.274 & 0.369 & -0.790 & 0.454 & -0.724 & 0.537 & 0.474 & 0.047 & 0.446 & 0.346 & 0.356 & 0.698 \\
\hline$S D$ & 0.750 & 0.809 & 0.746 & 0.857 & 0.776 & 0.737 & 0.802 & 0.705 & 0.792 & 0.807 & 0.933 & 0.772 & 0.762 & 0.837 & 0.518 \\
\hline
\end{tabular}

(Significance Level **: $1 \%, *: 5 \%$ )

Next, the correlation analysis of the satisfaction level and each principal component of the explanatory variables was conducted for the Taiwanese student who traveled to Japan. The result is as in table 4. For the consumer-behavior process, there was a significant correlation only with "Attention." For quality of service, there was a significant correlation with the three items of "empathy," "assurance," and "reliability." In addition, for experience value, there was a significant correlation with the three items of "esthetics," "education," and "escapism." In addition, convenience had a significant correlation. Generally, it can be said that quality of service and experience value can raise the satisfaction level of an overseas trip rather than consumer-behavior processes, such as advertising and promotion.

\section{Consideration}

Based on the result of the analysis of the questionnaire administered to Taiwanese students visiting Japan, various subjects related to tourism in Japan are considered. A Taiwanese student has high expectations and interest in an overseas trip. Since the Taiwanese student is eager for information gathering and an exchange about an overseas trip, they have remarkable information and heuristic knowledge about the tourist sites in Japan, and are considered to be familiar with both the good and bad points.

The Taiwanese students are evaluating the tourist sites in Japan for the quality of the premises, toilet, etc. and the staff's polite manner. Although it seems that these are good points for tourist sites in Japan, they are only a part in cases where the whole pleasure of a trip is considered. Although it became clear from the result of the analysis of the questionnaire that the satisfaction level of a tourist site is raised by the quality of service and the experience value, it cannot be said that many of the tourist sites in Japan are excellent as compared with other tourist sites. If these weak points are not improved, the number of international tourists that increased suddenly in recent years with the low yen rate may fall back according to future economic and environmental trends.

For example, it is effective for quality of service to raise not only "assurance" but "reliability" and "empathy" from the result of the questionnaire. The idea that tourist sites in Japan are excellent for quality of service with the reception manner of the Japanese "OMOTENASI" style may be a misapprehension of Japanese people. The traits of the reception manner of the "OMOTENASI" style are modesty, conservativeness, humbleness, deference, and the nonchalant stiff-upper-lip service, etc. However, such a manner sometimes appears perfunctory and impersonal to international tourists, and may be insufficient. Although it may change with a customer or statuses, the reform measure of adding flexible communication exceeding habitual service can be considered. For example, staff may find out about a customer's individual likes and concerns positively, and may also be able to sympathize and express this. In addition, staff members may positively approach the international visitor who is in trouble, showing their concern and may be able to solve in a kind manner. 
In addition, it seems that there is a margin for improving the "escapism" or "education" in tourist sites in Japan from the results of the analysis of the questionnaire about the experience economy. For example, Kyoto, Nara, Kamakura, etc. which are the typical tourist sites in Japan are former capitals, and are the so-called historic areas. However, though it is a historic area, it is difficult to experience the historical environment where historical scenes, such as a shrines and temples, including Buddhist temples, and modern buildings are intermingled, with telegraph poles and electricity cables spread around the old city. Another example is the many beach resorts, where a huge industrial complex, such as a power station, are within the field of view, and so it is not easy to experience "escapism". In addition, Japanese people are classified as having a highly context cultural style, and are not forthcoming in their communication. Such a Japanese communication trait may have an adverse effect on the goal of "education" in an experience value. Furthermore, in Japan, foreign language teaching has not been successful up to now, and the lack of ability and hesitation in communicating in a foreign language may also have adverse effects on tourism.

Although the discussion on expanding accommodation, transportation network improvements, etc. is in the mainstream in tourism policy at present, the redevelopment of the rows of stores and houses in a tourist site, etc. may be hurried. In addition, countermeasures in not only hard infrastructure but also soft infrastructure, such as educating and utilizing talented people in the tourism industry, may be important. For example, in the case of Japan, only someone who holds a state qualification called the "Licensed guide" can guide an international tourist for counter value. Reforming the regulations so that broadly talented people with the capability of various educational guidance and explanation for international tourists may also be necessity. Furthermore, reforming education systems towards the expansion of the service of talented people engaged in the tourism industry, such as universities and specialist schools, may also be effective.

\section{Conclusions}

This research has clarified empirically the factors that raise the satisfaction level of international tourists to Japan. It turned out that the factors that constitute especially quality of service and experience value are closely related to a revisit intention etc., based on the questionnaire to Taiwanese students with experience of visiting Japan. In addition, as compared with other countries, the factors by which tourist sites in Japan were evaluated highly, and the factors that were not evaluated highly became clear among those factors. As implication of the research, the factors effective in increasing the number of international tourists coming to Japan was shown quantitatively. As a limitation of this research, the object of this research is only Taiwanese university students who were studying Japanese, and the results may have a potential for sampling bias. I hope to aim at acquiring more wide-ranging knowledge by expanding the object for survey as a future subject.

\section{REFERENCES}

[1] Japan National Tourism Organization. Trend of the number of visitors from abroad, online available from www.jnto.go.jp/jpn/reference/tourism_data/visitor_trends, 2016.

[2] T. E. Barry. The Development of the Hierarchy of Effects: An Historical Perspective. Current Issues and Research in Advertising, 10(1-2), pp. 251-295, 1987.

[3] Dentsu. AISAS, registration-of-trademark number No. 4874525, 2005.

[4] A. Parasuraman, V. A. Zeithaml, \& L. L. Berry. SERVQUAL. Journal of Retailing, 64(1), 12-40, 1988.

[5] B. J. Pine, \& J. H. Gilmore. The experience economy: work is theatre $\&$ every business a stage. MA: Harvard Business Press, 1999.

[6] K. N. Lemon, \& P. C. Verhoef. Understanding Customer Experience Throughout the Customer Journey. Journal of Marketing, 80 (6), pp. 69-96, 2016.

[7] K. Dziewanowska. Dimensions of Real and Virtual Consumer Experiences. Faculty of Management Working Paper Series/University of Warsaw, (4), pp. 1-55, 2015.

[8] V. A. Zeithaml, M. J. Bitner, \& D. D. Gremler. Services Marketing. NY: McGraw Hill, 1996.

[9] V. A. Zeithaml, L. L.Berry, and A. Parasuraman. Problems and Strategies in Services Marketing. Journal of Marketing, 49 (Spring), 33-46, 1985.

[10] J. Carlzon. Moments of Truth, FL: Ballinger, 1987. 